\title{
Graduated effects of high-altitude hypoxia and highland ancestry on birth size
}

\author{
Rudy Soria', Colleen G. Julian², Enrique Vargas' ${ }^{1}$ Lorna G. Moore ${ }^{3}$ and Dino A. Giussani ${ }^{4}$
}

BACKGROUND: We present a cohort of ca. 25,000 birth records from Bolivia of men and women who are currently adults. We used this cohort to test the hypothesis that high altitude reduces birth weight and that highland ancestry confers graduated protection against this effect.

METHODS: Birth records were obtained from obstetric clinics and hospitals in La Paz (3,600 m) and Santa Cruz (420 m). Only singleton, healthy term (>37 $\mathrm{wk}$ ) pregnancies of nonsmoking mothers were included. Andean, Mestizo, or European ancestry was determined by validated analysis of parental surnames. RESULTS: High altitude reduced body weight $(3,396 \pm 3$ vs. $3,090 \pm 6 \mathrm{~g})$ and length $(50.8 \pm 0$ vs. $48.7 \pm 0 \mathrm{~cm})$ at birth $(P<$ 0.001 ). Highland ancestry partially protected against the effects of high altitude on birth weight (Andean $=3,148 \pm 15 \mathrm{~g}$; Mestizo $=3,081 \pm 6 \mathrm{~g}$; and European $=2,957 \pm 32 \mathrm{~g}$; trend $P<0.001$ ) but not on birth length. The effects of high-altitude pregnancy on birth size were similar for male and female babies.

CONCLUSION: High altitude reduces birth weight and highland native ancestry confers graduated protection. Given previous studies linking reduced birth weight with increased risk of cardiovascular disease, further study is warranted to test whether adults from high-altitude pregnancy are at increased risk of developing cardiovascular disease.

$\mathrm{n}$ addition to the interaction between our genetic makeup and traditional lifestyle risk factors, such as smoking and obesity, it is now accepted that the quality of the environment in prenatal life programs cardiovascular health and the risk of developing heart disease (1). Overwhelming evidence derived from human studies dating back more than two decades and encompassing six continents now links development under suboptimal intrauterine conditions with low birth weight and increased rates of coronary heart disease and the metabolic syndrome (2-8). Epidemiologic studies relating the type of suboptimal intrauterine condition with physiological dysfunction in later life have largely focused on human populations undergoing alterations in maternal nutrition or on human pregnancy affected by maternal psychological stress or by exposure to stress hormones (9-11). This focus on the nutrient supply to the fetus or on maternofetal stress in humans is supported by a large number of investigations in experimental animal models demonstrating that cardiovascular dysfunction in adulthood can be programmed in pregnancy by inappropriate nutrition or by exposure to glucocorticoid excess $(1,12,13)$.

In addition to the alterations in maternal nutrition and maternal stress, fetal hypoxia is one of the most common suboptimal conditions in complicated pregnancy. More than 140 million people live at altitudes $>2,500 \mathrm{~m}$ where lowered oxygen availability has been shown to reduce fetal growth and birth weight, thus comprising the largest single human group at risk for fetal growth restriction. Of note, multigenerational highaltitude populations demonstrate protection against the effects of high-altitude hypoxia on fetal growth (14-18). Experimental studies in animal models support the likelihood that prenatal hypoxia can program cardiac, vascular, and metabolic dysfunction in the adult offspring (19-21), and that high-altitude ancestry protects against the effect of chronic hypoxic development on fetal growth (22).

To serve as a platform for investigating whether hypoxiainduced reductions in birth weight increase susceptibility to adult cardiovascular disease in humans, we have created a cohort of 24,827 birth records in Bolivia from individuals who are currently adults and were born from pregnancies of Andean, Mestizo, or European ancestry. In this study, we determined the following for this cohort: (i) the effects of highaltitude hypoxia on birth size and (ii) whether high-altitude native ancestry protected against such high-altitude-induced alterations.

\section{RESULTS}

High- relative to low-altitude pregnancy significantly reduced the body weight and the length of the baby at birth (Table 1). Babies born at high altitude also had significantly lower Apgar scores at $5 \mathrm{~min}$ than those born at low altitude (Table 1 ).

Although all babies born at high altitude weighed less than those born at elevations near sea level, those high-altitude babies with Andean ancestry were heavier than those of Mestizo families, who in turn were heavier than those from European families (Table 2 and Figure 1). Although high-altitude native ancestry conferred graduated protection against the effects

IInstituto Boliviano de Biología de Altura, La Paz, Bolivia; ${ }^{2}$ Department of Emergency Medicine, Altitude Research Center, University of Colorado, Denver, Colorado; ${ }^{3}$ Department of Obstetrics/Gynecology, University of Colorado, Denver, Colorado; ${ }^{4}$ Department of Physiology, Development and Neuroscience, University of Cambridge, Cambridge, UK. Correspondence: Dino A. Giussani (dag26@cam.ac.uk) 


\section{Articles $\mid$ Soria et al.}

Table 1. Effect of pregnancy at high altitude on birth size

\begin{tabular}{|c|c|c|c|c|c|}
\hline & \multicolumn{4}{|c|}{ Altitude } & \multirow[b]{2}{*}{$P$ altitude } \\
\hline & Low & $n$ & High & $n$ & \\
\hline Total records assessed & \multicolumn{2}{|c|}{19,262} & \multicolumn{2}{|c|}{5,565} & \\
\hline Birth length (cm) & $50.8 \pm 0$ & 17,791 & $48.7 \pm 0$ & 4,764 & $<0.001$ \\
\hline Apgar score at $5 \mathrm{~min}$ & $8.8 \pm 0.0$ & 9,873 & $8.0 \pm 0.0$ & 4,937 & $<0.001$ \\
\hline
\end{tabular}

Table 2. Effect of altitude and ancestry on birth size for males and females

\begin{tabular}{|c|c|c|c|c|c|c|}
\hline & \multicolumn{4}{|c|}{ Altitude } & \multicolumn{2}{|c|}{$P$ values } \\
\hline & Low & $n$ & High & $n$ & Altitude & Altitude $\times$ ancestry \\
\hline \multicolumn{7}{|c|}{ Birth weight (g) } \\
\hline Andean & $3,402 \pm 17$ & 672 & $3,148 \pm 15$ & 728 & $<0.001$ & $<0.001$ \\
\hline Mestizo & $3,394 \pm 3$ & 18,064 & $3,081 \pm 6$ & 4,427 & & \\
\hline European & $3,442 \pm 22$ & 403 & $2,957 \pm 32$ & 167 & & \\
\hline Pancestry & NS & - & $<0.01$ & - & - & - \\
\hline \multicolumn{7}{|c|}{ Birth length $(\mathrm{cm})$} \\
\hline Andean & $50.7 \pm 0.1$ & 635 & $48.8 \pm 0.1$ & 710 & $<0.001$ & NS \\
\hline Mestizo & $50.8 \pm 0.0$ & 16,868 & $48.7 \pm 0.0$ & 3,902 & & \\
\hline European & $51.0 \pm 0.1$ & 241 & $48.5 \pm 0.3$ & 36 & & \\
\hline$P$ ancestry & NS & - & NS & - & - & - \\
\hline \multicolumn{7}{|c|}{ Ponderal index $\left(\mathrm{kg} \mathrm{m}^{-3}\right)$} \\
\hline Andean & $26.06 \pm 0.12$ & 624 & $27.02 \pm 0.10$ & 704 & $<0.001$ & NS \\
\hline Mestizo & $26.02 \pm 0.02$ & 16,708 & $26.77 \pm 0.04$ & 3,891 & & \\
\hline European & $25.63 \pm 0.19$ & 239 & $26.43 \pm 0.42$ & 35 & & \\
\hline$P$ ancestry & NS & - & $<0.05$ & - & - & - \\
\hline \multicolumn{7}{|l|}{ Male sex (\%) } \\
\hline All & $51.7(51.0,52.4)$ & $9,900 / 19,139$ & $50.9(49.6,52.2)$ & $2,709 / 5,322$ & NS & - \\
\hline Andean & $53.0(49.2,56.8)$ & $356 / 672$ & $47.9(44.3,51.5)$ & $349 / 728$ & NS & - \\
\hline Mestizo & $51.7(51.0,52.4)$ & $9,332 / 18,064$ & $51.3(49.8,52.8)$ & $2,271 / 4,427$ & NS & - \\
\hline European & $52.6(47.7,57.8)$ & $212 / 403$ & $53.3(45.7,60.9)$ & $89 / 167$ & NS & - \\
\hline$P$ ancestry & NS & - & NS & - & - & - \\
\hline
\end{tabular}

NS, not significant.

Values are mean \pm SEM or $95 \%$ confidence interval.

of highland pregnancy on birth weight, it did not ameliorate high-altitude-induced stunting of body length at birth (Table 2 and Figure 1). Consequently, babies born at high altitude of European ancestry were the thinnest for their length, thereby having the lowest ponderal index at birth (Table 2). The effects of high-altitude pregnancy and high-altitude ancestry on birth weight were similar among male and female babies (Table 3 and Table 4). The proportion of male vs. female infants in all ancestry groups was equal (Tables 1 and 2 ).

Plots of the cumulative frequency distribution across all birth-weight intervals showed a pronounced shift to the left in the curve of babies from high vs. low altitude, irrespective of ancestry (Figure 2). Babies born at high altitude of families with European ancestry were significantly left shifted relative to those of Mestizo families, who were significantly left shifted relative to those from Andean families (Figure 2). By contrast, high-altitude native ancestry did not affect birth weight in babies from low-altitude pregnancies (Figure 2).

\section{DISCUSSION}

In pregnancies complicated by maternal under- or over-nutrition or maternal stress, the environmental challenge does not necessarily transcend past one pregnancy or one generation. By contrast, the hypoxia of high altitude is constant, affecting 
pregnancies across generations. Populations established at high altitude are therefore unique, permitting the investigation of adaptive biological traits during pregnancy and early development to the common, selective pressure of exaggerated fetal hypoxia. Accordingly, many seminal studies have reported that pregnancy at high altitude not only leads to low birth weight (23-27), but that this effect is reduced in populations with a prolonged high-altitude native ancestry, as in Andeans and Tibetans (14-18). The selected advantageous traits of highaltitude native ancestry that reduce fetal growth restriction are so powerful that they overwhelm any additional detrimental effects of maternal malnutrition on fetal growth. In Bolivia, Andean relative to European populations are generally impoverished, with a continuing high prevalence of maternal malnutrition during pregnancy. This explains the apparent paradox of European financially affluent families giving birth to babies of lower weight than those of Andean families who are highly impoverished in La Paz (15). In this study, we confirm previous observations demonstrating a protective effect of Andean ancestry (15-17) in a larger population of birth records drawn from individuals who are now adults in Bolivia and can therefore be used for investigating the effect of high-altitude hypoxic pregnancy on the relationship between birth size and the developmental programming of disease in humans. This study also extends previous reports to show that high-altitude native ancestry confers graduated protection against the effects of high altitude on birth weight with the greatest effect evident in Andeans, intermediate in Mestizos, and least in babies of European families, and that this protection is selective for birth weight rather than birth length.

The mechanism of protection against high-altitude-induced fetal growth restriction due to highland ancestry is a subject of much interest. There are several candidate mechanisms, for which the most converging evidence supports differences in genetic factors affecting uteroplacental blood flow, placental function, and/or antioxidant status. For instance, Bennett et al. have reported that the Andean baby's birth weight at high altitude was higher when the pregnancy was classified according to the father's rather than the mother's ancestry (17). Such findings not only support genetically determined protective mechanisms, but they also suggest differences according to genetic imprinting, in which maternally transmitted genes restrict but paternally transmitted genes enhance fetal growth. Multiple independent groups have also shown that
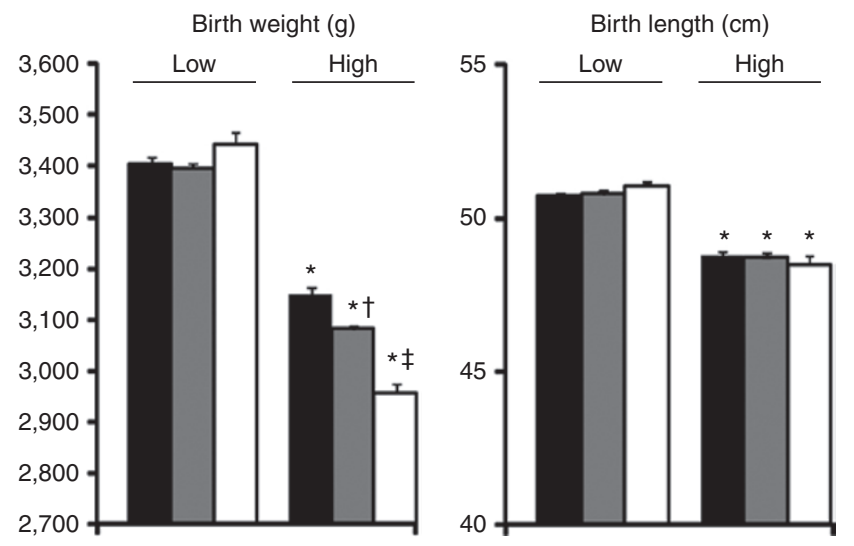

Figure 1. Effect of pregnancy at high altitude on birth size by ancestry. Values are mean \pm SEM for birth weight (left) and birth length (right) for babies born at low or high altitude from Andean (black histogram), Mestizo (gray histogram), or European (white histogram) ancestry. Significant differences $(P<0.05)$ are as follows: ${ }^{*}$ high vs. low; ${ }^{\dagger}$ Mestizo vs. Andean; and "European vs. Mestizo or Andean (general linear model analysis of variance, see text for details).

Table 3. Effect of altitude on birth size by ancestry for males only

\begin{tabular}{|c|c|c|c|c|c|c|}
\hline & \multicolumn{4}{|c|}{ Altitude } & \multicolumn{2}{|c|}{$P$ values } \\
\hline & Low & $n$ & High & $n$ & Altitude & Altitude $\times$ ancestry \\
\hline \multicolumn{7}{|c|}{ Birth weight (g) } \\
\hline Mestizo & $3,451 \pm 5$ & 9,332 & $3,139 \pm 9$ & 2,271 & $<0.001$ & $<0.001$ \\
\hline European & $3,517 \pm 31$ & 212 & $3,009 \pm 45$ & 89 & & \\
\hline \multicolumn{7}{|c|}{ Birth length (cm) } \\
\hline Andean & $50.8 \pm 0.1$ & 338 & $49.2 \pm 0.1$ & 339 & & \\
\hline Mestizo & $51.0 \pm 0$ & 8,732 & $49.0 \pm 0$ & 2,016 & $<0.001$ & $<0.05$ \\
\hline European & $51.3 \pm 0.2$ & 134 & $49.3 \pm 0.5$ & 15 & & \\
\hline$P$ ancestry & $<0.05$ & - & NS & - & - & - \\
\hline European & $26.67 \pm 0.25$ & 133 & $25.44 \pm 0.62$ & 15 & & \\
\hline$P$ ancestry & NS & - & NS & - & - & - \\
\hline
\end{tabular}

NS, not significant.

Values are mean \pm SEM. 


\section{Articles | Soria et al.}

Table 4. Effect of altitude on birth size by ancestry for females only

\begin{tabular}{|c|c|c|c|c|c|c|}
\hline & \multicolumn{4}{|c|}{ Altitude } & \multicolumn{2}{|c|}{$P$ values } \\
\hline & Low & $n$ & High & $n$ & Altitude & Altitude $\times$ ancestry \\
\hline \multicolumn{7}{|c|}{ Birth weight (g) } \\
\hline Mestizo & $3,333 \pm 5$ & 8,671 & $3,020 \pm 8$ & 2,156 & $<0.001$ & $<0.01$ \\
\hline European & $3,454 \pm 31$ & 189 & $2,898 \pm 44$ & 78 & & \\
\hline \multicolumn{7}{|c|}{ Birth length $(\mathrm{cm})$} \\
\hline Andean & $50.7 \pm 0.1$ & 293 & $48.4 \pm 0.1$ & 371 & & \\
\hline Mestizo & $50.5 \pm 0$ & 8,077 & $48.3 \pm 0$ & 1,886 & $<0.001$ & NS \\
\hline European & $50.6 \pm 0.2$ & 105 & $47.9 \pm 0.4$ & 21 & & \\
\hline$P$ ancestry & NS & - & NS & - & - & - \\
\hline European & $25.53 \pm 0.29$ & 104 & $27.18 \pm 0.57$ & 20 & & \\
\hline$P$ ancestry & NS & - & $P<0.05$ & - & - & - \\
\hline
\end{tabular}

the gene encoding HIF-2 $\alpha, E P A S-1$, contains signatures of natural selection in Tibetan high-altitude populations (28-31). Furthermore, Bigham et al. have shown that the gene encoding PHD2, a key enzyme in the normoxia-associated degradation of HIF-1 $\alpha$, EGLN1, has undergone selection in both Tibetans and Andeans, further supporting a genetic basis likely involving the HIF pathway underlying the native highlander advantage (31). It is also known that high altitude impairs the pregnancy-associated increase in uterine blood flow, but this defect is significantly diminished in highland native pregnancies (18). Another interesting possibility is one of placental reprogramming, raised by Zamudio and Illsley, which supports the preferential anaerobic consumption of glucose by the placenta for protecting fetal oxygen delivery at altitude (32). It is possible that this placentofetal oxygen sparing is greater in the Andean than European placenta. Julian et al. (33) have reported a greater increase in catalase and superoxide dismutase in blood from Andean relative to European pregnant women, supporting a role for elevated maternal enzymatic antioxidant status mediating the protection of Andeans against the high-altitude-associated fall in birth weight. It is also possible that a number of these candidate mechanisms may be interrelated. For instance, genetically determined increases in maternal antioxidant status may increase NO bioavailability, favoring perfusion in circulations which are highly dependent on the vasodilator gas, such as the uteroplacental vascular bed, thereby protecting nutrient and oxygen delivery to the fetus.

The data in this study showing the graduated highland ancestry protection on birth weight but not on birth length highlight that the effects of altitude and ancestry occurred across the whole continuum of birth weights measured. Such observations have many commonalities with the original

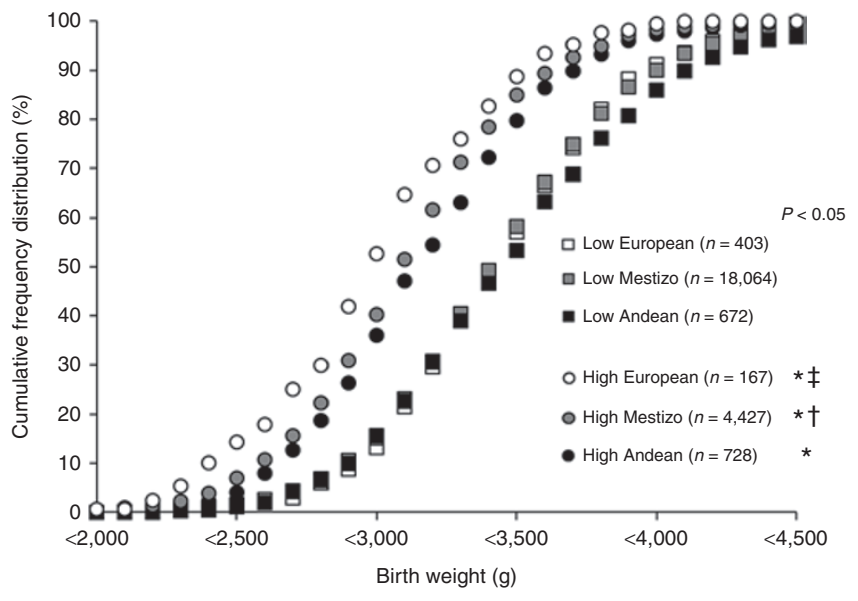

Figure 2. Cumulative frequency distribution. Values are the cumulative percentage of babies across weight intervals shown who were born at low or high altitude of Andean, Mestizo, or European ancestry. Significant differences $(P<0.05)$ are as follows: ${ }^{*}$ high vs. low; ${ }^{\dagger}$ Mestizo vs. Andean; "European vs. Mestizo or Andean (general linear model analysis of variance).

findings of Barker et al. (2) who found phenotypic associations between asymmetric fetal growth restriction and elevated cardiovascular risk factors in human populations in the United Kingdom (and subsequently elsewhere), and that this relationship also extended through the normal range of birth weights. The shape of the baby, particularly the differential effects of adverse intrauterine conditions on weight and length at birth, has drawn increasing interest. Phillips et al. (34) described that men and women who were thin for their length at birth were more often insulin resistant. Whereas longitudinal growth is linear, absolute fetal weight gain in the fetus is exponential 
with advancing gestation. Therefore, suboptimal intrauterine conditions may impact the baby's weight more than its length, yielding the thin-for-length infant shape. This thrifty phenotype also results in adverse pregnancy from the redistribution of the fetal cardiac output away from nonessential circulations, including those perfusing the fetal pancreas, toward essential vascular beds, such as the fetal brain. Consequently, it has been suggested that thin-for-length babies may be born with a reduced $\beta$-cell mass, reduced islet vascularization, and an impaired insulin response; effects which are all compatible with a switch to insulin resistance in later life (34). In this study, babies of European ancestry born at high altitude not only showed the most pronounced reduction in birth weight, but they also had the greatest percentage of clinically defined intrauterine growth retardation $(<2,500 \mathrm{~g})$ and they also were the thinnest for their length, thereby having the lowest ponderal index at birth. One limitation of the study is the lower number of birth records obtained from the European population in La Paz given that this is necessarily a smaller population than the majority of the inhabitants of high altitude in Bolivia, who are largely of indigenous ancestry. Nevertheless, the data suggest that adults from high-altitude pregnancy of European ancestry to be the most susceptible for developing cardiometabolic dysfunction, including the insulin resistance syndrome, and for Andean ancestry to protect against this effect. Data on the prevalence of cardiometabolic morbidity and mortality in highland populations are lacking, particularly in studies controlling for high-altitude native ancestry. However, it is known that the human heart undergoes ventricular hypertrophy at altitude (35), that diabetes is a significant public health problem in Bolivia (36), and that patients with chronic mountain sickness in La Paz have marked systemic vascular dysfunction with evidence of impaired peripheral vasodilatation, increased arterial stiffness, and carotid arterial wall thickening (37). It is also known that individuals of Andean ancestry show protection against diabetes and chronic mountain sickness at high altitude $(36,38)$. However, whether low birth weight is related to increased cardiometabolic morbidity in high-altitude native and nonnative populations awaits investigation.

In summary, we present a cohort of ca. 25,000 Bolivian birth records of Andean, Mestizo, and European men and women who are currently adults. The data in this cohort show that high altitude reduces birth weight and birth length, and that highland native ancestry confers graduated protection against impaired weight but not length at birth in a sex-independent manner. Further study is warranted to determine whether altitude-associated reductions in birth weight raise the risk of adult onset cardiovascular disease and, if so, whether such an increase in disease risk varies by ancestry.

\section{METHODS}

\section{Bolivia}

Bolivia is well placed for this investigation. While the Andean Cordillera runs through the west of the country, eastern parts encompass rainforest regions that span into the Brazilian Amazon. Consequently, Bolivia is divided into several highland $(>2,500 \mathrm{~m})$ and lowland $(<500 \mathrm{~m})$ regions. The two most populated Bolivian cities, La $\mathrm{Paz}(3,649 \mathrm{~m})$ and Santa Cruz $(437 \mathrm{~m})$, are among the highest and the lowest in the country, with La Paz being the highest capital city in the world. Bolivia is largely inhabited by individuals of mixed descent, with families of Andean, Mestizo, and European ancestry.

\section{Study Design}

All procedures were approved by the Local Ethics Committee of the Bolivian Institute for High Altitude Biology (Consejo Técnico, Instituto Boliviano de Biología de Altura, Universidad Mayor de San Andrés, La Paz, Bolivia). Using a multiinstitutional approach, records from deliveries spanning a decade between 1975 and 1985 were obtained over 2 y from obstetric clinics and hospitals in the cities of $\mathrm{La} \mathrm{Paz}$ and Santa Cruz. In La Paz, records were obtained from La Caja Nacional de la Salud, El Hospital de la Mujer, La Clínica Torrico, and La Clínica Terán. In Santa Cruz, records were obtained from El Hospital Percy Boland, El Hospital $1^{\circ}$ de Mayo, La Clínica Lourdes, and La Clínica Foianini. These institutions were selected because they were the centers providing prenatal care to the largest number of women in their respective communities. Only singleton, nonsmoking healthy pregnancies that reached term $(>37 \mathrm{wk})$ were included. Birth records with insufficient information about health history, birth weight, or gestational age were excluded from the analysis.

\section{Ancestry Classification}

In Bolivian custom, infants acquire both paternal and maternal surnames and women do not change their surname upon marriage, yielding as many as four parental surnames for each infant. Infant ancestry was classified retrospectively using parental surnames with a methodology validated by gene markers, as described elsewhere (39). Surnames were classified as "Andean" if they were of Aymara or Quechua origin, "Foreign" if they were non-Andean and nonHispanic, and "Mestizo" for all other cases. Because $>90 \%$ of foreign names were of European origin, this category was identified as "European." Hispanic surnames were classified as Mestizo rather than as European, unless there was clear evidence of European origin (e.g., Spanish nationality). This rationale stemmed from previous studies in which we were not able to accurately predict non-Andean ancestry using Hispanic surnames. More specifically, in some cases, even women with two non-Andean, Hispanic surnames (e.g., Garcia) were found to be $100 \%$ Amerindian according to ancestry informative genetic markers (39). By contrast, Andean surname frequency (e.g., Condori, Mamani, or Huanca) is strongly correlated with high altitude in Bolivia $(39,40)$.

We first adopted a conservative approach in surname analysis in which only records containing at least two parental surnames were analyzed. Although this strategy provided a robust ancestry classification, it reduced the sample size significantly. In particular, the high-altitude European group was significantly affected because the paternal/maternal dual surname system is not always used in that population. Further analysis revealed that grouping records according to either one or two surnames available (e.g., when infants with one or two Andean surnames were both classified as "Andean" or when infants with one or two European surnames were both classified as "European") produced similar results. We therefore elected to include records with one or two surnames for ancestry classification. This decision was further supported by a previous study in which we reported assortative mating patterns in Bolivia as indicated by a strong positive correlation between maternal and paternal ancestry and very few marriages between individuals with two Andean and two European surnames (17). The possible surname combinations for each ancestry classification were therefore as follows: Andean when one or two surnames were Andean (i.e., Andean or Andean-Andean), European if one or two surnames were European (i.e., European or EuropeanEuropean), or Mestizo if surnames were Mestizo, Mestizo-Mestizo, European-Andean, Mestizo-European, or Mestizo-Andean.

\section{Data and Statistical Analyses}

Ponderal index was calculated as infant body weight/body length ${ }^{3}$ at birth. Data are reported as mean \pm SEM or $95 \%$ confidence intervals for proportions. In addition, the cumulative frequency distribution across all birth weights was plotted for each of the ancestry groups from La Paz and Santa Cruz. Univariate linear mixed models were 
used for identifying the effect of high altitude and highland ancestry on birth size. Comparisons between altitude and ancestry groups were made using the Student's $t$-test for continuous variables and the $\chi^{2}$ test for nominal variables (SPSS, Chicago, IL). For all comparisons, significance was accepted when the two-tailed $P<0.05$.

\section{ACKNOWLEDGMENTS}

We are grateful to the following people for their help in this study: Jaime Terán, Guillermo Torrico, Roberto Bohrt, Lieselotte Bauer de Barragán, David Asturizaga, Carmelo Rodriguez, Maria Luz Almendros, Beatriz Duran, and Jorge Foianini.

\section{STATEMENT OF FINANCIAL SUPPORT}

This study was financially supported by the British Heart Foundation, The Royal Society, UK (D.G.), and the National Institutes of Health (NIH, USA; NIHHLBI-079647 (L.M.)).

\section{REFERENCES}

1. Gluckman PD, Hanson MA, Cooper C, Thornburg KL. Effect of in utero and early-life conditions on adult health and disease. N Engl J Med 2008;359:61-73.

2. Barker DJP, Osmond C, Winter PD, Margetts B, Simmonds SJ. Weight in infancy and death from ischaemic heart disease. Lancet 1989;ii:577-80.

3. Rich-Edwards JW, Stampfer MJ, Manson JE, et al. Birth weight and risk of cardiovascular disease in a cohort of women followed up since 1976. BMJ 1997;315:396-400.

4. Leon DA, Lithell HO, Vâgerö D, et al. Reduced fetal growth rate and increased risk of death from ischaemic heart disease: cohort study of 15 000 Swedish men and women born 1915-29. BMJ 1998;317:241-5.

5. Fall CH, Stein CE, Kumaran K, et al. Size at birth, maternal weight, and type 2 diabetes in South India. Diabet Med 1998;15:220-7.

6. Huang RC, Mori TA, Beilin LJ. Early life programming of cardiometabolic disease in the Western Australian pregnancy cohort (Raine) study. Clin Exp Pharmacol Physiol 2012;39:973-8.

7. Levitt NS, Lambert EV. The foetal origins of the metabolic syndrome-a South African perspective. Cardiovasc J S Afr 2002;13:179-80.

8. Silva AA, Santos CJ, Amigo H, et al. Birth weight, current body mass index, and insulin sensitivity and secretion in young adults in two Latin American populations. Nutr Metab Cardiovasc Dis 2012;22:533-9.

9. Roseboom TJ, van der Meulen JH, Ravelli AC, et al. Blood pressure in adults after prenatal exposure to famine. J Hypertens 1999;17: 325-30.

10. Eskenazi B, Marks AR, Catalano R, Bruckner T, Toniolo PG. Low birthweight in New York City and upstate New York following the events of September $11^{\text {th }}$. Hum Reprod 2007;22:3013-20.

11. Dalziel SR, Walker NK, Parag V, et al. Cardiovascular risk factors after antenatal exposure to betamethasone: 30 -year follow-up of a randomised controlled trial. Lancet 2005;365:1856-62.

12. McMillen IC, Robinson JS. Developmental origins of the metabolic syndrome: prediction, plasticity, and programming. Physiol Rev 2005;85: 571-633.

13. Seckl JR, Meaney MJ. Glucocorticoid programming. Ann N Y Acad Sci 2004;1032:63-84.

14. Haas JD, Frongillo EF, Stepcik C, Beard J, Hurtado L. Altitude, ethnic and sex differences in birthweight and length in Bolivia. Hum Biol 1980;52:459-77.

15. Giussani DA, Phillips PS, Anstee S, Barker DJ. Effects of altitude versus economic status on birth weight and body shape at birth. Pediatr Res 2001;49:490-4.

16. Julian CG, Vargas E, Armaza JF, Wilson MJ, Niermeyer S, Moore LG. High-altitude ancestry protects against hypoxia-associated reductions in fetal growth. Arch Dis Child Fetal Neonatal Ed 2007;92:F372-7.
17. Bennett A, Sain SR, Vargas E, Moore LG. Evidence that parent-oforigin affects birth-weight reductions at high altitude. Am J Hum Biol 2008;20:592-7.

18. Moore LG, Charles SM, Julian CG. Humans at high altitude: hypoxia and fetal growth. Respir Physiol Neurobiol 2011;178:181-90.

19. Patterson AJ, Zhang L. Hypoxia and fetal heart development. Curr Mol Med 2010;10:653-66.

20. Rueda-Clausen CF, Morton JS, Davidge ST. The early origins of cardiovascular health and disease: who, when, and how. Semin Reprod Med 2011;29:197-210.

21. Giussani DA, Camm EJ, Niu Y, et al. Developmental programming of cardiovascular dysfunction by prenatal hypoxia and oxidative stress. PLoS ONE 2012;7:e31017.

22. Giussani DA, Salinas CE, Villena M, Blanco CE. The role of oxygen in prenatal growth: studies in the chick embryo. J Physiol (Lond) 2007;585(Pt 3):911-7.

23. Lichty JA, Ting RY, Bruns PD, Dyar E. Studies of babies born at high altitudes. I. Relation of altitude to birth weight. AMA J Dis Child 1957;93:666-9.

24. Beall CM. Optimal birthweights in Peruvian populations at high and low altitudes. Am J Phys Anthropol 1981;56:209-16.

25. Jensen GM, Moore LG. The effect of high altitude and other risk factors on birthweight: independent or interactive effects? Am J Public Health 1997;87:1003-7.

26. Mortola JP, Frappell PB, Aguero L, Armstrong K. Birth weight and altitude: a study in Peruvian communities. J Pediatr 2000;136:324-9.

27. Gonzales GF, Tapia V. Birth weight charts for gestational age in 63,620 healthy infants born in Peruvian public hospitals at low and at high altitude. Acta Paediatr 2009;98:454-8.

28. Beall CM, Cavalleri GL, Deng L, et al. Natural selection on EPAS1 (HIF2alpha) associated with low hemoglobin concentration in Tibetan highlanders. Proc Natl Acad Sci USA 2010;107:11459-64.

29. Yi X, Liang Y, Huerta-Sanchez E, et al. Sequencing of 50 human exomes reveals adaptation to high altitude. Science 2010;329:75-8.

30. Simonson TS, Yang Y, Huff CD, et al. Genetic evidence for high-altitude adaptation in Tibet. Science 2010;329:72-5.

31. Bigham AW, Mao X, Akey JM, et al. Identifying signatures of natural selection in Tibetan and Andean populations using dense genome scan data. PLoS Genetics 2010;6:1-14.

32. Zamudio S, Torricos T, Fik E, et al. Hypoglycemia and the origin of hypoxiainduced reduction in human fetal growth. PLoS ONE 2010;5:e8551.

33. Julian CG, Vargas E, Browne VA, et al. Potential role for elevated maternal enzymatic antioxidant status in Andean protection against altitude-associated SGA. J Matern Fetal Neonatal Med 2012;25:1233-40.

34. Phillips DI, Barker DJ, Hales CN, Hirst S, Osmond C. Thinness at birth and insulin resistance in adult life. Diabetologia 1994;37:150-4.

35. Peñaloza D, Arias-Stella J. The heart and pulmonary circulation at high altitudes: healthy highlanders and chronic mountain sickness. Circulation 2007;115:1132-46.

36. Barceló A, Daroca MC, Ribera R, Duarte E, Zapata A, Vohra M. Diabetes in Bolivia. Rev Panam Salud Publica 2001;10:318-23.

37. Rimoldi SF, Rexhaj E, Pratali L, et al. Systemic vascular dysfunction in patients with chronic mountain sickness. Chest 2012;141:139-46.

38. Stuber T, Scherrer U. Circulatory adaptation to long-term high altitude exposure in Aymaras and Caucasians. Prog Cardiovasc Dis 2010;52: $534-9$.

39. Vargas M, Vargas E, Julian CG, et al. Determinants of blood oxygenation during pregnancy in Andean and European residents of high altitude. Am J Physiol Regul Integr Comp Physiol 2007;293:R1303-12.

40. Rodriguez-Larralde A, Dipierri J, Gomez EA, et al. Surnames in Bolivia: a study of the population of Bolivia through isonymy. Am J Phys Anthropol 2011;144:177-84. 